\title{
Surface Kinetics of Copper Oxidation Investigated by In Situ Ultra-high Vacuum Transmission Electron Microscopy
}

\author{
Judith C. Yang, ${ }^{*}$ Mridula D. Bharadwaj, Guangwen Zhou, and Lori Tropia \\ Department of Materials Science and Engineering, University of Pittsburgh, Pittsburgh, PA 15261
}

\begin{abstract}
We review our studies of the initial oxidation stages of $\mathrm{Cu}(001)$ thin films as investigated by in situ ultra-high vacuum transmission electron microscopy. We present our observations of surface reconstruction and the nucleation to coalescence of copper oxide during in situ oxidation in $\mathrm{O}_{2}$. We have proposed a semi-quantitative model, where oxygen surface diffusion is the dominant mechanism of the initial oxidation stages of $\mathrm{Cu}$. We have also investigated the effect of water vapor on copper oxidation. We have observed that the presence of water vapor in the oxidizing atmosphere retards the rate of $\mathrm{Cu}$ oxidation and $\mathrm{Cu}_{2} \mathrm{O}$ is reduced when exposed directly to steam.
\end{abstract}

Key words: in situ, transmission electron microscopy, oxidation, $\mathrm{Cu}, \mathrm{Cu}_{2} \mathrm{O}$, water vapor

\section{INTRODUCTION}

We are investigating the initial oxidation of copper by in situ ultra-high vacuum (UHV) transmission electron microscopy (TEM) to gain insights into the atomistic mechanisms of metal oxidation. TEM provides nanoscale information-from surface reconstruction and nucleation of metal oxides to the coalescence of an oxide scale. These methods permit visualization of oxidation processes in real time and provide insights into the buried surfaces. In situ TEM techniques have been used in the past to investigate the initial oxidation stages of metals, such as $\mathrm{Ni}$ alloys (Hobbs and Mitchell, 1981), Fe (Hobbs and Mitchell, 1981), NiCr (Marikar et al., 1989), and TiAl alloys (Elsch et al., 1990), as well as $\mathrm{Cu}$ (Milne and Howie, 1984). However, we have carried out our in situ TEM experiments under

Received January 10, 2001; accepted May 9, 2001.

L. Tropia is currently at Sylvania Industries, New Hempshire, PA.

${ }^{*}$ Corresponding author better vacuum conditions $\left(10^{-8}\right.$ torr base pressure) than the previous investigations, so that surface contamination effects are minimized.

We chose $\mathrm{Cu}$ as a model metal system since it is a simple face centered cubic metal, and due to its application as a preferred interconnect material for ULSI (ultra-large scale integrated circuits), owing to its low electrical resistivity and improved resistance to electromigration (Ohba, 1995). Two types of oxides $-\mathrm{CuO}$ and $\mathrm{Cu}_{2} \mathrm{O}$ - have been reported to form on $\mathrm{Cu}(001)$ (Roennquist and Fischmeister, 1960-61).

This review is presented in two sections. The first section focuses on dry oxygen experiments, where we examine $\mathrm{Cu}$ oxidation over a wide range of partial pressures and temperatures. We find that heteroepitaxial concepts, based on surface diffusion, describe our observations surprisingly well. We have developed a semi-quantitative model to explain our observations of the initial oxidation stage of $\mathrm{Cu}$. In this stage, oxygen surface diffusion is the dominant pro- 
cess for transport and nucleation (Yang et al., 1998a) and oxygen surface diffusion plus direct impingement describe the initial growth of $\mathrm{Cu}_{2} \mathrm{O}$ (Yang et al., 1997a). We are presently applying the Johnson-Mehl-Avrami-Kolmogorov (JMAK) surface theory to describe nucleation to coalescence of copper oxides, and we find good agreement.

In the second section, we discuss our studies on copper oxidation with water vapor. Previous investigators have reported that water vapor changes the kinetics of metal oxidation. Water vapor increases the oxide scaling rate of iron by a factor of 1.2 and 1.6 at 850 and $950^{\circ} \mathrm{C}$, respectively (Rehmel and Tobolski, 1965). Sharp increases in the overall rate of oxidation of (001), (110), and (111) oriented silicon upon the addition of trace amounts of $\mathrm{H}_{2} \mathrm{O}$ have been reported by Irene et al. (1974). Investigations of Si oxidation by Ross and Gibson (1992) confirmed the findings of Irene et al. (1974). In contrast with these reports, we observed the surprising reduction of $\mathrm{Cu}_{2} \mathrm{O}$ on exposure to water vapor.

\section{Materials and Methods}

Single crystal $99.999 \%$ pure $600-1000 \AA \mathrm{Cu}$ films were grown on irradiated rock salt substrates which were cleaved along the (001) plane in an UHV e-beam evaporation system (base pressure of $10^{-9}$ torr). This thickness was chosen so that the film was thin enough to be examined by the TEM, but thick enough for the initial oxidation behavior to be similar to that of bulk metal. The film was deposited at a rate of $5 \AA$ per sec and the substrate temperature was $250^{\circ} \mathrm{C}$. The $\mathrm{Cu}$ film was removed from the substrate by flotation in de-ionized water, washed and mounted on a silicon mount, where the modifications to the specimen holder permit the Si mount to resistively heat the specimen.

The microscope used was a modified JEOL 200CX with a spatial resolution of $2.5 \AA$ (McDonald et al., 1989). A leak valve attached to the column of the microscope allowed the introduction of gases directly into the microscope. In order to minimize the contamination, a UHV chamber was attached to the middle of the column, where the base pressure was less than $10^{-8}$ torr without the use of the cryoshroud. The cryoshroud inside the microscope column can further reduce the base pressure to around $10^{-9}$ torr when filled with liquid He. A video camera mounted at the base of the column recorded real-time pictures of the experiment. A 5 $\mu \mathrm{m}$ objective aperture was used in order to enhance the contrast of the dark field images. The microscope was operated at $100 \mathrm{keV}$ to minimize irradiation effects.
In addition to TEM, we have used atomic force microscopy (AFM) and scanning electron microscopy (SEM) to examine the surface topology, where the specimen was removed from the in situ TEM and placed into a SEM (Hitachi S-800) or AFM (Digital Instruments Dimension 3100 AFM).

The $\mathrm{Cu}$ film forms a native oxide on the surface due to air exposure, which could be removed by annealing the $\mathrm{Cu}$ film at $350^{\circ} \mathrm{C}$ for $15 \mathrm{~min}$ (Yang et al., 1997b). However, to remove the oxide formed on the $\mathrm{Cu}$ surface, due to in situ oxidation, the specimen was annealed at $350^{\circ} \mathrm{C}$ and then exposed to methanol gas at $5 \times 10^{-5}$ torr column pressure. Methanol reacts with the adsorbed oxygen atoms to form a methoxy species, which is bound to the $\mathrm{Cu}$ surface by $\mathrm{O}$ atom. At $350^{\circ} \mathrm{C}$, the methoxy species decomposes to give gaseous formaldehyde and water vapor [Eq. (1)] (Francis et al., 1994):

$$
\mathrm{CH}_{3} \mathrm{OH}_{\mathrm{g}}+[\mathrm{O}]_{\mathrm{ad}} \Rightarrow \mathrm{HCHO}+\mathrm{H}_{2} \mathrm{O}_{\mathrm{g}} .
$$

Scientific grade oxygen gas of $99.999 \%$ purity could be introduced into the TEM chamber at a partial pressure between $5 \times 10^{\% 5}$ torr and 760 torr, and temperature between 25 and $600^{\circ} \mathrm{C}$. For oxidation experiments above $5 \times$ $10^{-4}$ torr, it is essential to isolate the column from the electron source and then evacuate the column of the microscope before the TEM is used to take the images.

To study the effect of water vapor on the clean $\mathrm{Cu}$ film, water vapor ( $99.9 \%$ purity) was introduced directly into the $\mathrm{TEM}$, at a partial pressure of $5 \times 10^{-4}$ torr and $350^{\circ} \mathrm{C}$. In another experiment, scientific grade oxygen gas $(99.999 \%$ purity) was introduced into the TEM at a partial pressure of $5 \times 10^{-4}$ torr at $350^{\circ} \mathrm{C}$ for up to $8 \mathrm{~min}$. The oxygen supply was then discontinued and water vapor was leaked into the column under similar temperature and pressure conditions. To study the effect of simultaneous exposure to $\mathrm{O}_{2}$ and $\mathrm{H}_{2} \mathrm{O}$ vapor, we opened both leak valves to let in $\mathrm{O}_{2}$ and water vapor at a total pressure of $5 \times 10^{-4}$ torr and $350^{\circ} \mathrm{C}$.

The micrographs were digitized with an UMAX-Astra 1220U scanner. The software packages Adobe Photoshop 5.0, Digital Micrograph, and Scion Image 1.62c were used to analyze the experimental data.

\section{Dry OXIDATION With $\mathrm{O}_{2}$}

\section{Surface Reconstruction}

It is important to study the role of surface reconstruction in the nucleation of metal oxides, as previous investigators 


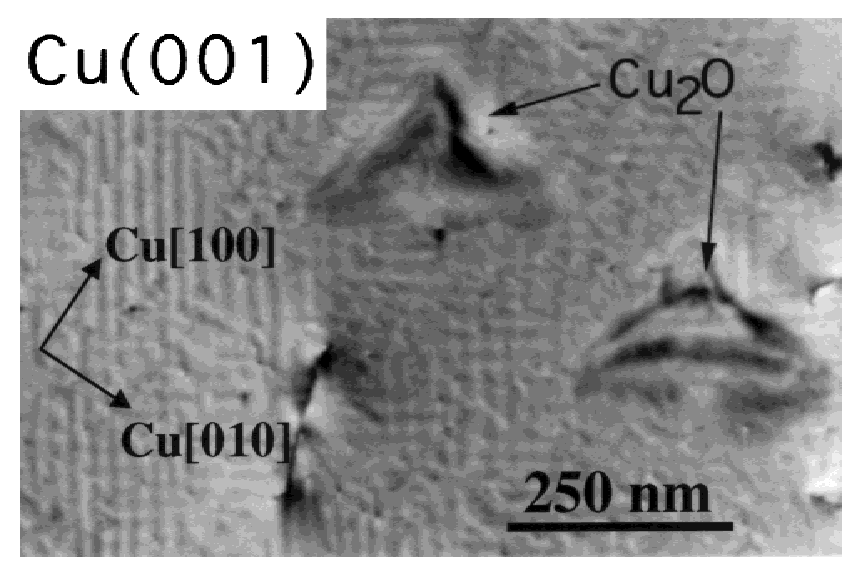

Figure 1. $\mathrm{Cu}(200)$ dark field image after oxygen has been introduced into the microscope at $5 \times 10^{-4}$ torr oxygen and $450^{\circ} \mathrm{C}$. Pronounced strain contrast due to surface reconstruction is clearly visible.

have speculated that a surface saturated layer must form before the onset of oxide formation (Heinneman et al., 1975). Figure 1 (Yang et al., 1998b) is a $\mathrm{Cu}(200)$ dark field image after $\mathrm{Cu}$ film was exposed to oxygen at $5 \times 10^{-4}$ torr partial pressure and $450^{\circ} \mathrm{C}$. It shows pronounced strain contrast due to the anisotropic $\mathrm{Cu} \sqrt{2} \times 2 \sqrt{2} \mathrm{R} 45$ surface reconstruction (Tanaka et al., 1998). The oxide nucleation occur on the reconstructed $\mathrm{Cu}-\mathrm{O}$ surface and, hence, the surface topology and factors that influence it should significantly alter the initial stages of oxidation.

\section{Low-pressure Oxidation: Nucleation and Initial Oxide Growth}

We have examined initial nucleation stages of $\mathrm{Cu}$ under a wide range of pressure and temperature conditions. Figure $2 \mathrm{a}$ is a dark field image taken from the $\mathrm{Cu}_{2} \mathrm{O}(110)$ reflection after the $\mathrm{Cu}$ film has been cleaned. No oxide islands are visible in this region. Figure $2 \mathrm{~b}, \mathrm{c}$ shows subsequent dark field images, taken from the $\mathrm{Cu}_{2} \mathrm{O}(110)$ diffraction spot of the same area as shown in the Figure $2 \mathrm{a}$ of the $\mathrm{Cu}$ film, at successive 10-min time increments after $\mathrm{O}_{2}$ was leaked into the column at a partial pressure of $5 \times 10^{-4}$ torr and the sample temperature was at $350^{\circ} \mathrm{C}$. After a dwell time of $\sim 2$ min, when the $\mathrm{Cu}$ surface reconstructed due to the exposure to oxygen, the oxide islands were seen to nucleate rapidly followed by mainly growth. The selected area diffraction (SAD) pattern of the $\mathrm{Cu}$ film after oxidation can be indexed as $(001) \mathrm{Cu}_{2} \mathrm{O}$, where the relative orientation between the $\mathrm{Cu}_{2} \mathrm{O}$ and $\mathrm{Cu}$ film is $(001) \mathrm{Cu} / /(001) \mathrm{Cu}_{2} \mathrm{O}$ and $[100] \mathrm{Cu} / /[100] \mathrm{Cu}_{2} \mathrm{O}$ (Fig. 2d).
To describe this nucleation behavior, we applied the heteroepitaxial concept of a "zone of oxygen capture," where oxygen atoms that land within this zone can diffuse on the surface and be incorporated into an existing oxide island. Then the probability of an oxide nucleation event is proportional to the fraction of the available surface area outside these zones of capture [Eq. (2)]:

$$
\mathrm{dN}=\mathrm{k}\left(1-\mathrm{L}_{\mathrm{d}}^{2} \mathrm{~N}\right) \mathrm{dT}
$$

where, $\mathrm{N}$ is the number density of nuclei, $\mathrm{t}$ is time, $\mathrm{L}_{\mathrm{d}}{ }^{2}$ is the area of the zone of oxygen capture, where $L_{d} \gg$ than the diameter of the oxide island, and $\mathrm{k}$ is a proportionality constant, which depends on the probability for $\mathrm{Cu}$ and $\mathrm{O}$ to form $\mathrm{Cu}_{2} \mathrm{O}$. Using the boundary condition that at $\mathrm{t}=0, \mathrm{~N}$ $=0$, and solving the above linear differential equation, we obtain [Eq. (3)]:

$$
\mathrm{N}=1-\mathrm{e}^{-\mathrm{kL_{d }}{ }^{2}}
$$

Figure 3 is the experimental data and theoretical fit to Eq. (3). An excellent match is noted where the fit parameters, $\mathrm{k}=0.17 \mu \mathrm{m}^{-2} \mathrm{~min}^{-1}$ and $\mathrm{L}_{\mathrm{d}}=1.09 \mu \mathrm{m}$. Hence, the initial nucleation rate is $0.17 \mu \mathrm{m}^{-2} \mathrm{~min}^{-1}$ and the saturation island density, $1 / \mathrm{L}_{\mathrm{d}}{ }^{2}$ is $0.83 \mu \mathrm{m}^{-2}$.

To gain insights into the topology of the $\mathrm{Cu}$ oxide island, we used SEM and AFM. Figure 4a is a SEM image and Figure $4 \mathrm{~b}$ is the AFM image after oxidation at $5 \times 10^{-4}$ torr, $350^{\circ} \mathrm{C}$ and $5 \mathrm{~min}$, showing that the copper oxide islands grow above the $\mathrm{Cu}$ film too, as can be expected from the lattice mismatch of $15 \%$ between $\mathrm{Cu}$ and $\mathrm{Cu}_{2} \mathrm{O}$. The islands are not faceted planes, but are concave upwards. Also, an indentation exists between the $\mathrm{Cu}$ and $\mathrm{Cu}_{2} \mathrm{O}$ islands, suggesting the $\mathrm{Cu}$ is rapidly taken from the near vicinity of the oxide island during growth.

\section{High-pressure Oxidation: Self-limiting Oxidation}

Nearly all metals form a passivation film due to oxidation in air at ambient temperature. This film acts as a diffusion barrier to protect the materials from further corrosion. The classical theory of Cabrera and Mott (1948) describes the passivation film formation on metals, where they predict that this film grows as a uniform layer due to a fieldenhanced ionic transport mechanism. The Cabrera-Mott model predicts an inverse logarithmic growth rate for metal oxides, that formed due to outward cation diffusion [Eq. (4)], 

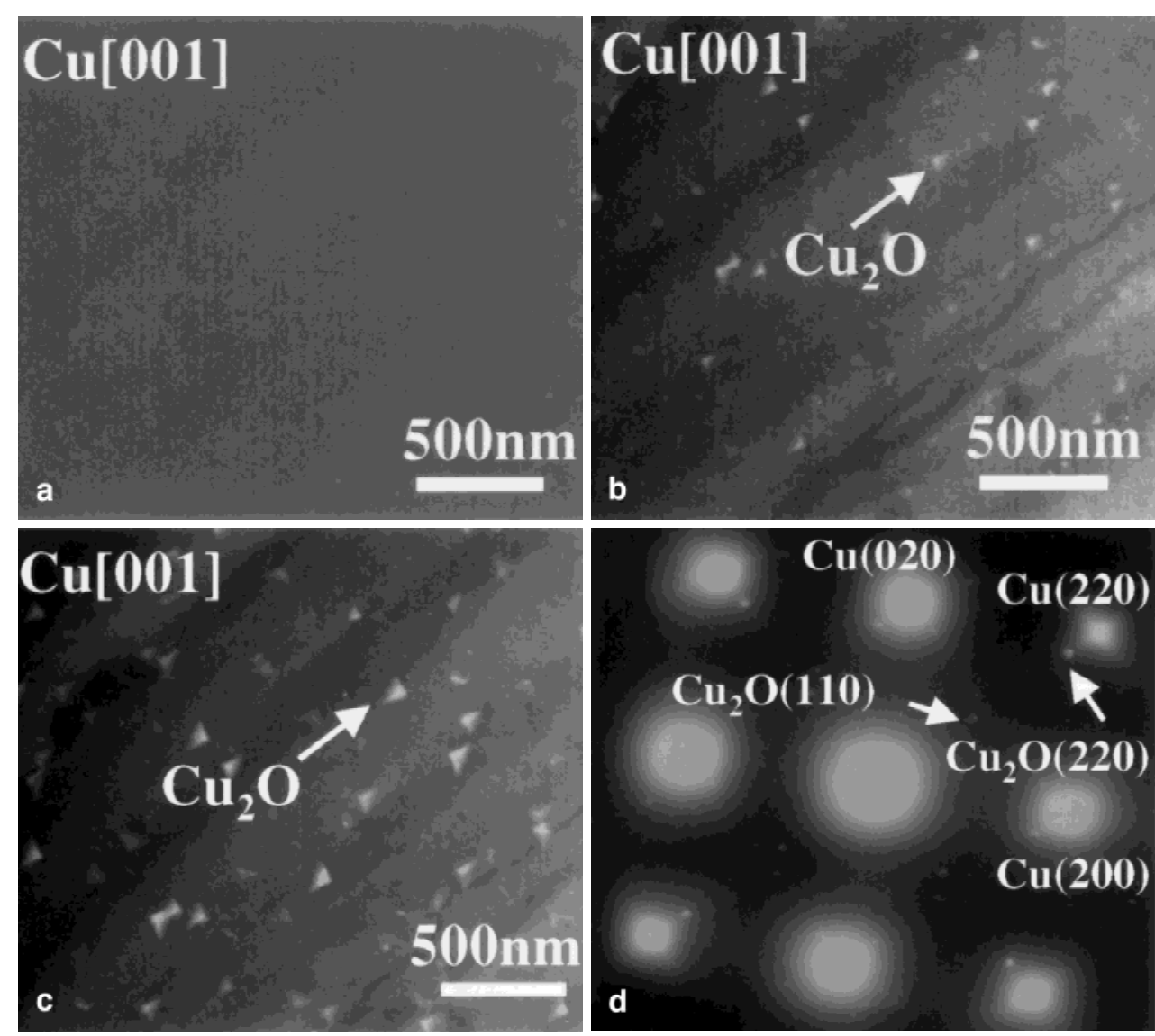

Figure 2. Dark field $\mathrm{Cu}_{2} \mathrm{O}(110)$ transmission electron microscopy (TEM) images after oxidation by $\mathrm{O}_{2}$ at $5 \times 10^{-4}$ torr pressure and $350^{\circ} \mathrm{C}$ for (a) $0 \mathrm{~min}$, (b) $10 \mathrm{~min}$, and (c) 20 min. Panel $\mathbf{d}$ is the selected area diffraction pattern from the $\mathrm{Cu}$ after oxidation. The additional diffraction spots are due to $\mathrm{Cu}_{2} \mathrm{O}$.

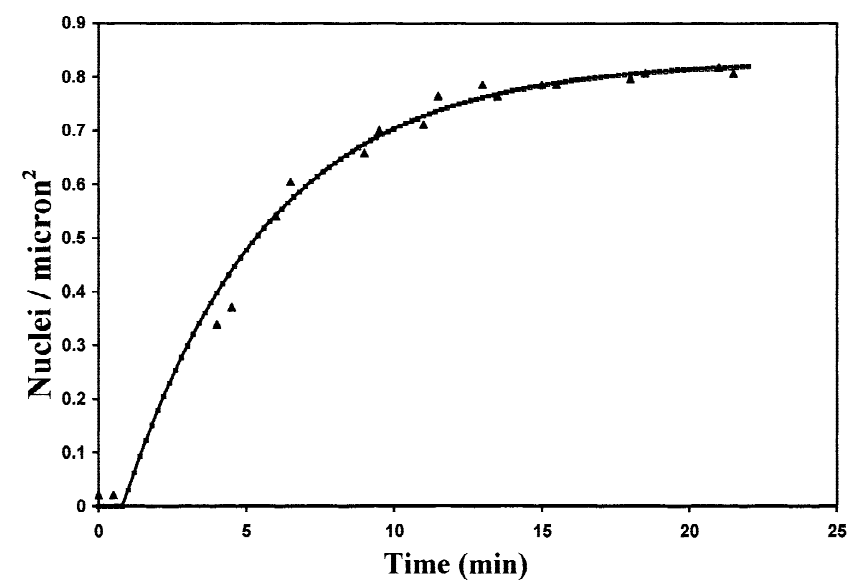

Figure 3. $\mathrm{Cu}_{2} \mathrm{O}$ island density as a function of time, when $\mathrm{O}_{2}$ was introduced at $5 \times 10^{-4}$ torr pressure and $350^{\circ} \mathrm{C}$.

$$
1 / x=A-B \ln t
$$

where $\mathrm{x}$ is the thickness of the oxide film, $\mathrm{t}$ is time, and A and $\mathrm{B}$ are the fit parameters. Figure 5 is a reproduction of Young et al.'s experimental data (1956) for $\mathrm{Cu}(001)$ com- bined with a fit to the above equation. We have shown that nucleation of oxide islands occurs even at atmospheric pressure (Yang et al., 1998c). Thus, here the Cabrera-Mott model, which assumes a uniformly growing film, cannot be valid. We have proposed that the self-limiting oxidation of $\mathrm{Cu}$ is due to the coalescence of islands, which "switches-off" the surface diffusion route. Bulk diffusion, which is significantly slower, is necessary for further oxidation following coalescence. Figure 6 is a sequence of dark field images for which the $\mathrm{Cu}$ film was oxidized at 0.1 torr and $350^{\circ} \mathrm{C}$. Here the oxide island formation followed by coalescence is clearly evident.

A standard theory, used in thin film growth, to describe nucleation to coalescence is the JMAK theory, which proposes that the nucleation and coalescence of thin films is due to surface processes (Johnson and Mehl, 1939; Avrami, 1940). It presumes that the coverage will follow an exponential dependency on time [Eq. (5)]:

$$
\mathrm{X}(\mathrm{t})=1-\exp \left(-\mathrm{kt} \mathrm{t}^{\mathrm{n}}\right)
$$

where $\mathrm{X}$ is the coverage, $\mathrm{t}$ is time, and $\mathrm{k}$ and $\mathrm{n}$ are fit parameters that depend on the surface mechanisms of 


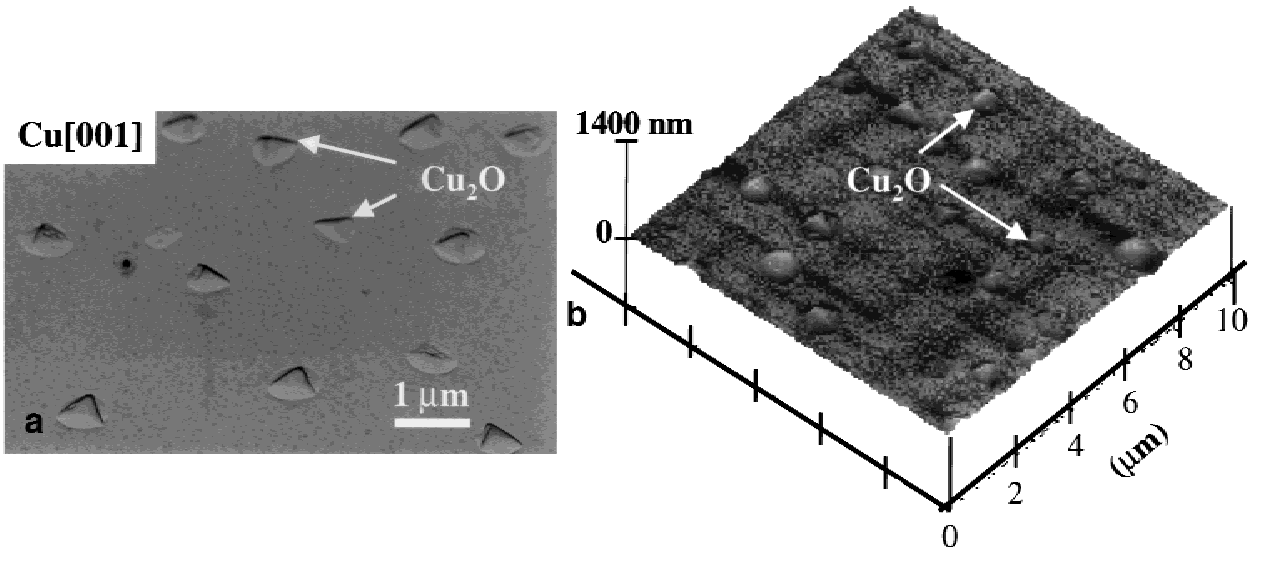

Figure 4. Surface topology of the $\mathrm{Cu}$ film as seen by (a) scanning electron microscopy and (b) atomic force microscopy after $\mathrm{Cu}$ film was oxidized in situ by $\mathrm{O}_{2}$ at $5 \times$ $10^{-4}$ torr pressure and $350^{\circ} \mathrm{C}$. The average height of the $\mathrm{Cu}_{2} \mathrm{O}$ islands was found to be $\sim 100$ $\mathrm{nm}$.

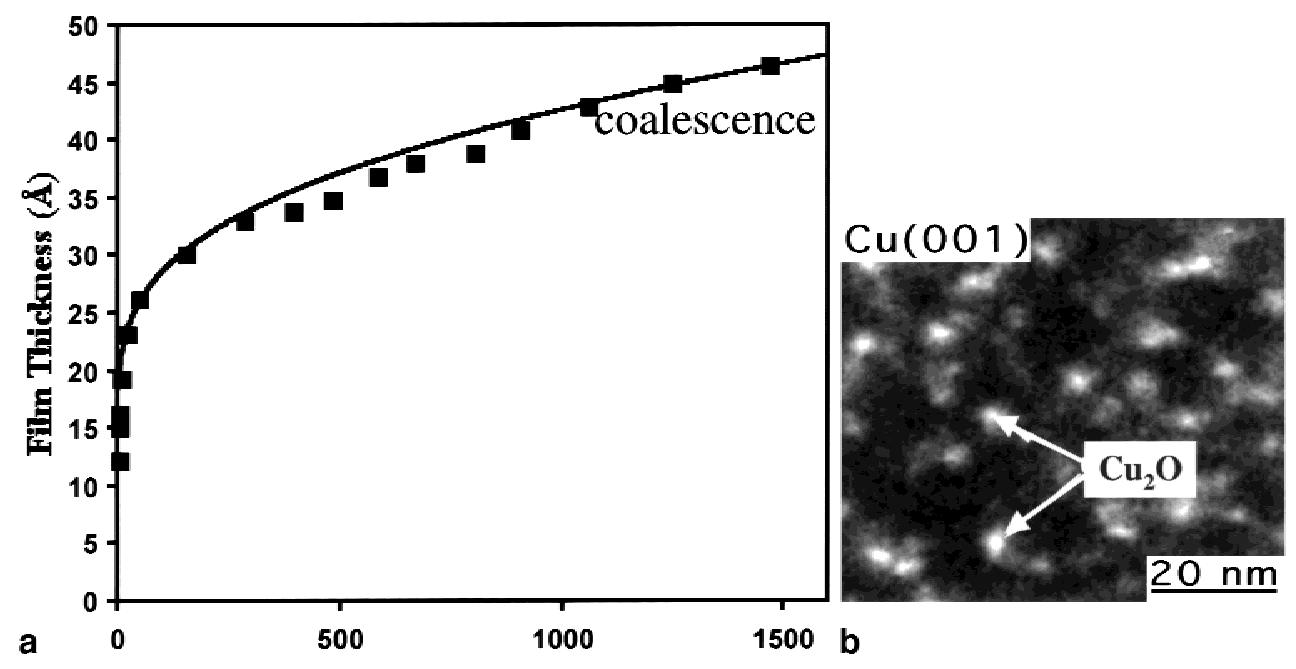

Figure 5. a: $\mathrm{Cu}_{2} \mathrm{O}$ thickness as a function of time from an experiment by Young et al. (1956), when single crystal (001) $\mathrm{Cu}$ was oxidized in 760 torr $\mathrm{O}_{2}$ at $70^{\circ} \mathrm{C}$. b: Dark field image from the $\mathrm{Cu}_{2} \mathrm{O}$ reflection, where the bright specks are $\mathrm{Cu}_{2} \mathrm{O}$ islands. transport, nucleation, and growth. The parameter, $\mathrm{n}$, is usually an integer or half-integer. For 3-D growth, theory predicts fit parameters of $\mathrm{k}=\pi / 3$ and $\mathrm{n}=4$ (Weinberg et al., 1997), assuming constant nucleation and uniform radial growth rate. Figure 7 is the plot of the fractional coverage of the copper oxide with respect of time. The circles are the experimental data. The solid line is the best fit to the JMAK formula [Eq. (5)], where the fit parameters are: $\mathrm{k}=1.9 \times$ $10^{-4}$ and $\mathrm{n}=2$, and the goodness of fit, $\mathrm{R}=0.99$. The slower rate for copper oxidation as compared to Weinburg et al.'s calculation is reasonable because the growth and nucleation rate of $\mathrm{Cu}_{2} \mathrm{O}$ islands is not linear and constant, respectively. $\mathrm{Cu}$ has been shown (Yang et al., 1997a) to have a radial growth rate of $\mathrm{r} \propto \mathrm{t}^{0.65}$ which is slower than the linear growth rate. The nucleation of $\mathrm{Cu}_{2} \mathrm{O}$ islands occurs almost instantly and not continually with time (Yang et al., 1998c). Both of these factors will lead to a slower nucleation to coalescence as compared to the JMAK calculation for 3-D growth with constant nucleation and growth rate. Another possible reason for such a small $\mathrm{k}$ is that the growth rate is very slow for copper oxidation. It was noted that the sticking coefficient is extremely small indicating that only a few oxygen atoms are contributing to the growth of the copper oxides.

\section{OXIDATION IN WATER VAPOR}

When methanol cleaning was directly followed by water vapor exposure, no reaction between $\mathrm{Cu}$ and water vapor was observed. We then oxidized $\mathrm{Cu}(100)$ in dry oxygen to form $\mathrm{Cu}_{2} \mathrm{O}$. Figure $8 \mathrm{a}$ is the dark field image taken from $\mathrm{Cu}_{2} \mathrm{O}(110)$ reflection after exposure to oxygen at total column pressure of $5 \times 10^{-4}$ torr and $350^{\circ} \mathrm{C}$ for $8 \mathrm{~min}$, showing $\mathrm{Cu}_{2} \mathrm{O}$ islands. After $8 \mathrm{~min}$, the oxygen supply was discontinued and water vapor was introduced at the same pressure and temperature. Figure $8 \mathrm{~b}, \mathrm{c}$ shows the subsequent dark field images taken from $\mathrm{Cu}_{2} \mathrm{O}(110)$ diffraction spot show- 

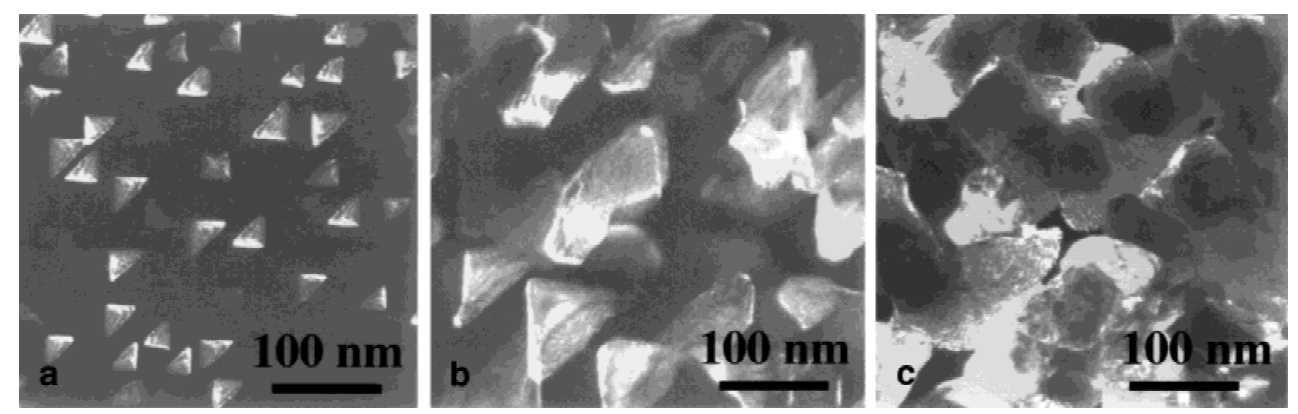

Figure 6. Dark field images from the $\mathrm{Cu}_{2} \mathrm{O}$ reflection showing (a) $\mathrm{Cu}_{2} \mathrm{O}$ island nucleation, (b) growth, and then (c) coalescence when $\mathrm{Cu}(001)$ was oxidized by 0.1 torr $\mathrm{O}_{2}$ at $350^{\circ} \mathrm{C}$.

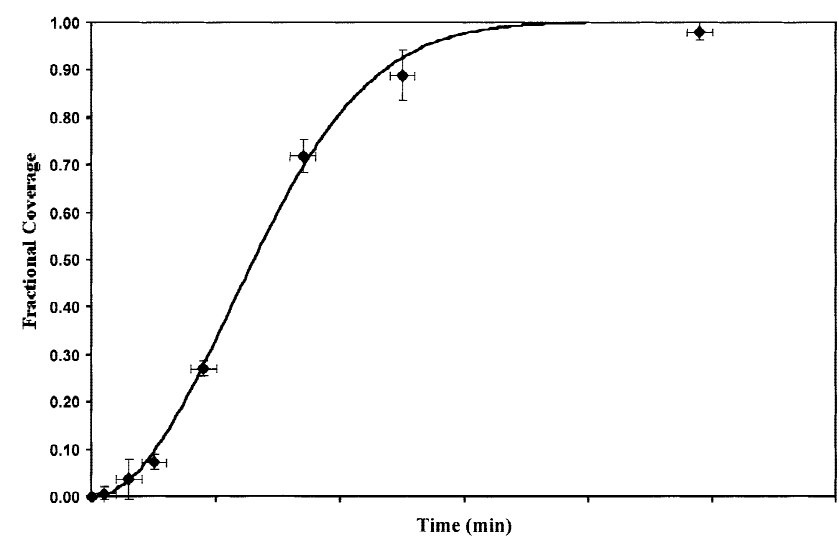

Figure 7. Plot of fractional coverage of oxide on the $\mathrm{Cu}$ surface with respect to oxidation time when $\mathrm{Cu}(001)$ was oxidized by dry $\mathrm{O}_{2}$ at 0.1 torr and $350^{\circ} \mathrm{C}$.

ing partial (after 2 min of water vapor exposure) and complete (after $9 \mathrm{~min}$ of water vapor exposure) reduction of oxide islands, respectively. Figure 8d,e shows the SAD patterns of the $\mathrm{Cu}$ film after oxidation (d), followed by exposure to water vapor (e).

We also investigated the effect of simultaneous exposure of the $\mathrm{Cu}$ film to oxygen and water vapor on the rate of $\mathrm{Cu}$ oxidation. We observed that moist $\mathrm{O}_{2}$ oxidized $\mathrm{Cu}$ significantly slower than dry $\mathrm{O}_{2}$. Figure 9 shows a comparative plot of density of oxide islands with respect to time of exposure to dry and moist $\mathrm{O}_{2}$ atmospheres at a total pressure of $4 \times 10^{-4}$ torr at $350^{\circ} \mathrm{C}$. The $\mathrm{P}\left(\mathrm{O}_{2}\right)$ inside the column due to the $\mathrm{O}_{2}$ and water vapor mixture is calculated to be $3.4 \times 10^{-4}$ torr. The dramatic decrease in the oxidation rate was surprising since the calculated $\mathrm{P}\left(\mathrm{O}_{2}\right)$ for the $\mathrm{O}_{2}+\mathrm{H}_{2} \mathrm{O}$ was only $15 \%$ less than that for dry $\mathrm{O}_{2}$ exposure.

At $350^{\circ} \mathrm{C}$, the dissociation pressure for cuprous oxide is $10^{-18}$ torr (Pearson, 1985). The calculated $\mathrm{P}\left(\mathrm{O}_{2}\right)$ due to dissociation of water into $\mathrm{O}_{2}$ and $\mathrm{H}_{2}$, is $10^{-14}$ torr when only $\mathrm{H}_{2} \mathrm{O}(\mathrm{g})$ is leaked inside the microscope column at a total column pressure of $4 \times 10^{-4}$ torr. Hence, oxidation of

$\mathrm{Cu}$ is expected when exposed to water vapor, but no oxide nucleation was observed despite the availability of the required amount of oxygen. A possible explanation of this could be that the bulk thermochemical data do not take into account the interfacial free energies $\left(\sigma_{\text {Cu-oxide }}+\right.$ $\left.\sigma_{\text {oxide-vapor }}\right)$, which would alter the desorption pressure of $\mathrm{Cu}_{2} \mathrm{O}$. For example, the strain energy between $\mathrm{Cu}$ and $\mathrm{Cu}_{2} \mathrm{O}$, which contributes to the total interfacial free energy, could be relieved by reduction to the unstrained $\mathrm{Cu}$ free surface.

In terms of the surface chemical reactions, we speculate that the water vapor reacts with the $\mathrm{Cu}_{2} \mathrm{O}$ to form $\mathrm{CuOH}$. We propose the following reaction scheme for the $\mathrm{Cu}_{2} \mathrm{O}$ reduction [Eqs. $(6,7)]$ :

$$
\mathrm{Cu}_{2} \mathrm{O}+\mathrm{H}_{2} \mathrm{O} \geq 2 \mathrm{CuOH}
$$

$$
2 \mathrm{CuOH} \geq 2 \mathrm{Cu}+\mathrm{H}_{2}+\mathrm{O}_{2} .
$$

Further, we examined the role of possible trace impurities and residual gasses in the TEM column to see if these could explain our observations. We considered the reaction of gaseous formaldehyde, produced via methanol oxidation, with oxygen formed by dissociation of water vapor. From our estimation of the amount of formaldehyde available for the reaction with $\mathrm{O}_{2}$, the presence of formaldehyde could explain why $\mathrm{Cu}$ oxidation does not occur, but cannot explain the reduction of $\mathrm{Cu}_{2} \mathrm{O}$. We next considered the possible role of carbon. The liquid He cryoshroud was used to reduce the base pressure of the TEM by an order of magnitude $\left(10^{-8}\right.$ to $10^{-9}$ torr). Again we observed the reduction of $\mathrm{Cu}_{2} \mathrm{O}$ within $9 \mathrm{~min}$ of water vapor exposure. If $\mathrm{C}$ played a key role in reducing $\mathrm{Cu}_{2} \mathrm{O}$, then reducing the amount of carbon should have altered the experimental observation significantly, at least the rate, which we did not observe. Heating at $700^{\circ} \mathrm{C}$ did not cause evaporation of $\mathrm{Cu}_{2} \mathrm{O}$, ruling out purely annealing effects. Oxidation experiments with 

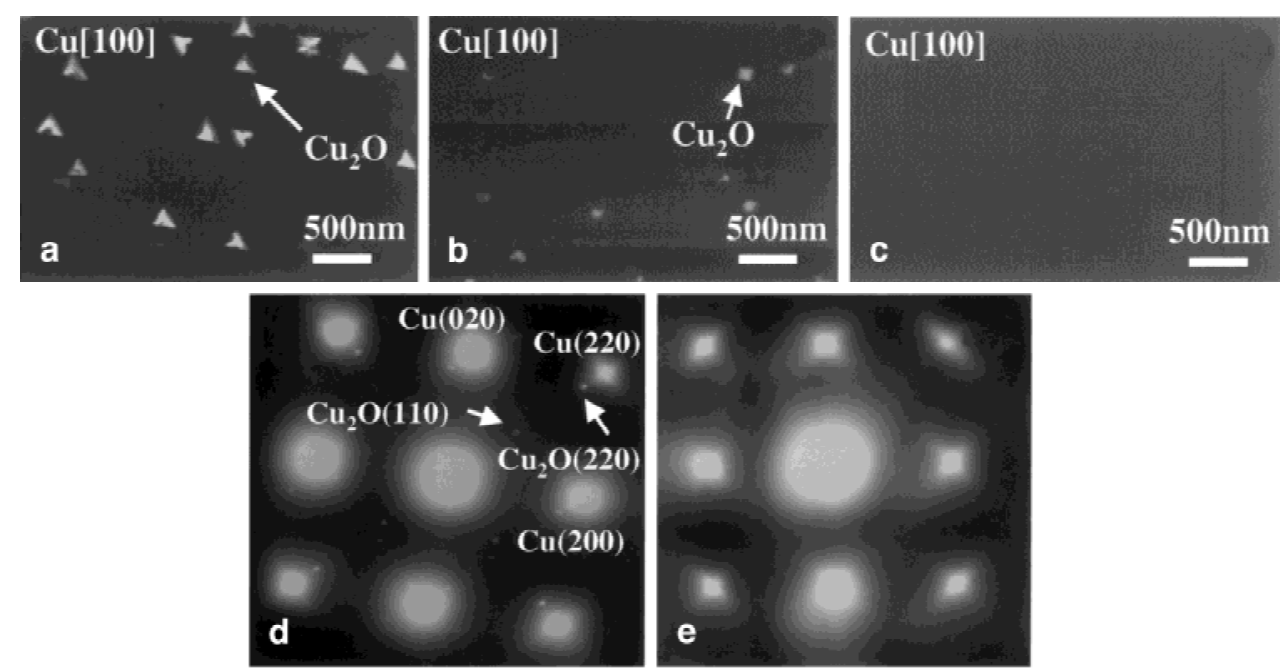

Figure 8. Dark field $\mathrm{Cu}_{2} \mathrm{O}(110)$ TEM images on exposures to (a) $\mathrm{O}_{2}$, at $5 \times 10^{-4}$ torr pressure and $350^{\circ} \mathrm{C}$ for $8 \mathrm{~min}$, and later, to water vapor for (b) 2 min and (c) 9 min under similar pressure and temperature conditions. Also shown are the selected area diffraction patterns of $\mathrm{Cu}$ film (d) before and (e) after water vapor exposure.

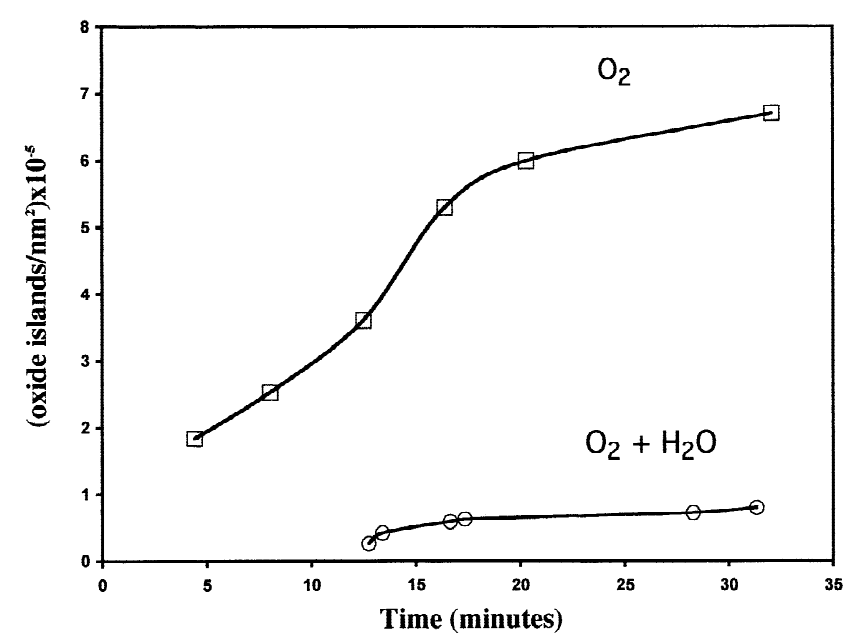

Figure 9. Plot of $\mathrm{Cu}_{2} \mathrm{O}$ island density as a function of time for oxidation of $\mathrm{Cu}$ film in dry oxygen at $4 \times 10^{-4}$ torr pressure and $350^{\circ} \mathrm{C}$, and oxygen plus water vapor under similar pressure and temperature conditions.

and without the e-beam were conducted and the same $\mathrm{Cu}_{2} \mathrm{O}$ reduction process was found to occur, thus ruling out the reduction being an electron beam effect.

\section{CONCLUSIONS}

The initial oxidation stages of $\mathrm{Cu}$ have been investigated by in situ ultra-high vacuum TEM techniques under a wide range of oxidizing pressures and temperatures, and in dry oxygen as well as water vapor. We find that surfaces play a key role in metal oxidation.
Under dry oxygen, surface reconstruction was indirectly observed prior to the onset of nucleation of oxide. $\mathrm{Cu}_{2} \mathrm{O}$ islands were observed to grow three-dimensionally and epitaxially with respect to the $\mathrm{Cu}$ film. We have demonstrated that oxygen surface diffusion is the dominant mechanism for the oxide nucleation and growth. Heteroepitaxial concepts, used to describe thin film formation, are surprisingly synergistic with the initial stages of $\mathrm{Cu}$ oxidation, from nucleation behavior ("zone of oxygen capture") to coalescence (JMAK theory).

We also speculate that surfaces and interfaces at the nanoscale can explain our observations of $\mathrm{Cu}$ and $\mathrm{Cu}$ oxides in a water vapor environment. The presence of moisture in the oxidizing atmosphere retarded the rate of $\mathrm{Cu}$ oxidation. The exposure to water vapor caused the unexpected reduction of $\mathrm{Cu}_{2} \mathrm{O}$. We speculate that this is due to interfacial and surface energies that can alter the thermochemistry as compared to bulk.

Our future goals include: continuing the water vapor experiments under better surface conditions, so as to further minimize the role played by impurities; examining the effect of other oxidizing atmospheres, such as ozone and atomic $\mathrm{O}$; and studying other materials, such as $\mathrm{Al}$ and other orientations of $\mathrm{Cu}$.

\section{ACKNOWLEDGMENTS}

This research project is funded by the National Science Foundation (DMR \#9902863) and the Department of Energy (DEF02-96ER45439). Experimental facilities were provided at the Materials Research Laboratory, University of 
Illinois at Urbana-Champaign. We are thankful to J.M. Gibson, M. Yeadon, C. Zimmermann, M. Menzes, and H. Birnbaum for their contributions.

\section{References}

Avrami M (1941) Kinetics of phase change-III. J Chem Phys 9:177-184

Basenbacher F, Jensen F, Laegsgaard E, Mortensen K, Stensgaard I (1991) Visualization of the dynamics in surface reconstructions. $J$ Vac Sci Technol B 9:874-878

Cabrera N, Mott NF (1948) Theory of oxidation of metals. Rep Prog Phys 12:163-184

Elsch I, Friedman SL, Kahveci AI (1990) In situ TEM investigations of the oxidation of titanium aluimide alloys. In: Microscopy of Oxidation. Cambridge, UK: Cambridge University, The Institute of Metals, pp 193-205

Francis SM, Leibsle FM, Haq S, Xiang N, Bowker M (1994) Methanol oxidation on $\mathrm{Cu}(110)$. Surf Sci 15:284-292

Heinemann K, Rao DB, Douglas DL (1975) Oxide nucleation on thin films of copper during in situ oxidation in an electron microscope. Oxid Met 9:379-400

Hobbs LW, Mitchell TE (1981) Studies of metal oxidation by transmission electron microscopy. In: High Temperature Corrosion. San Diego, CA: NACE, pp 76-83

Irene EA (1974) J Electrochem Soc 121:1614-1616

Johnson WA, Mehl R (1939) Reaction kinetics in processes of nucleation and growth. Trans Metall Soc AIME 415

Marikar P, Brodsky MB, Sowers CH, Zaluzec NJ (1989) In situ HVEM studies of the early stages of oxidation of nickel and nickelchromium alloys. Ultramicroscopy 29:247-256

McDonald ML, Gibson JM, Unterwald FC (1989) Design of an ultrahigh-vacuum specimen environment for high resolution transmission electron microscopy. Rev Sci Instrum 60:700-707
Milne RH, Howie A (1984) Electron microscopy of copper oxidation. Phil Mag A 49:665-682

Ohba T (1995) Advanced multilevel metallization technology. Appl Surf Sci 91:1-11

Orr WH (1962) Oxide nucleation and growth [thesis], Ithaca, NY: Cornell University

Rahmel A, Tobolski J (1965) Corros Sci 5:333-346

Roennquist A, Fischmeister H (1960-61) The oxidation of copper. J Inst Met 89:65-76

Ross FM, Gibson JM (1992) Dynamic observations of interface propagation during silicon oxidation. Phys Rev Lett 68:1782-1785

Tanaka KI, Fujita T, Okawa Y (1998) Oxygen induced orderdisorder restructuring of $\mathrm{Cu}(100)$ surface. Surf Sci 401:L407-L412

Twesten RD, Gibson JM, Ross FM (1994) Visualization of dynamic near-surface processes. MRS Bull 19:38-43

Yang JC, Yeadon M, Kolasa B, Gibson JM (1997a) Oxygen surface diffusion in three-dimensional $\mathrm{Cu}_{2} \mathrm{O}$ growth on $\mathrm{Cu}(001)$ thin films. Appl Phys Lett 70:3522-3524

Yang JC, Yeadon M, Olynick D, Gibson JM (1997b) Anomalous desorption of copper oxide observed by in situ transmission electron microscopy. Microsc Microanal 3:121-125

Yang JC, Yeadon M, Kolasa B, Gibson JM (1998a) The homogeneous nucleation mechanism of $\mathrm{Cu}_{2} \mathrm{O}$ on $\mathrm{Cu}(001)$. Scripta Materialia 38:1237-1242

Yang JC, Yeadon M, Kolasa B, Gibson JM (1998b) Surface reconstruction and oxide nucleation due to oxygen interaction with $\mathrm{Cu}(001)$ observed by in situ ultra high vacuum transmission electron microscopy. Microsc Microanal 4:334-339

Yang JC, Kolasa B, Gibson JM (1998c) Self limiting oxidation of copper. Appl Phys Lett 73:2841-2843

Young F, Cathcart J, Gwathmey A (1956) The rates of oxidation of several faces of a single crystal of copper as determined with elliptically polarized light. Acta Metall 4:145

Weinberg MC, Birnie DP, Shneidman VA (1997) Crystallization kinetics and the JMAK equation. J Non-crystalline Solids 219:89-99 